\title{
Survey of disbudding practice on Czech dairy farms
}

\author{
S. Staněk,${ }^{* 1}$ R. Šárová,† E. Nejedlá, ${ }^{*}$ S. Šlosárková,ł and O. Doležal§ \\ *Department of Technology and Breeding Technique of Farm Animals, Institute of Animal Science, Přátelství 815, 10400 Prague 10-Uhříněves, \\ Czech Republic \\ †Department of Ethology, Institute of Animal Science, Přátelství 815, 10400 Prague 10-Uhříněves, Czech Republic \\ fDepartment of Immunology, Veterinary Research Institute, Hudcova 296/70, 62100 Brno, Czech Republic \\ §Dairy cattle specialist, K Sokolovně, 10400 Prague 10-Uhříněves, Czech Republic
}

\begin{abstract}
Disbudding is a routine practice in many dairy herds due to the effort to decrease the risk of injuries. Although the disbudding practice is regulated, it can vary among farms. The variation may be caused by many factors, such as herd size or type of breed, but also by farmers' perception of pain caused by disbudding. Hence, the aim of this study was to specify the disbudding practice on dairy farms in the Czech Republic and to assess these practices, including the use of pain mitigation medication, by breed, herd size, and sex of the disbudded calves. We analyzed data from 106 Czech dairy farms, which were collected by a trained interviewer at dairy meetings in 2014-2015. The farmers answered questions regarding the farm's basic characteristics, disbudding practice, and his/her attitude to the pain caused by disbudding. To test the influence of breed, herd size, and sex of disbudded calves on different variables, logistic regression models were used. Disbudding was performed in $92.5 \%$ of the surveyed farms; $63.3 \%$ of dairy calves were disbudded before 4 wk of age, and Czech Fleckvieh calves were 2.8 times more likely to be disbudded before 4 wk of age than Holstein calves. The hot-iron method was the most used method (69.4\%). Calves were 4.5 times more likely to be disbudded by hot iron in herds where both heifers and bulls were disbudded than in herds where only heifers were disbudded. Most (>90\%) surveyed farms did not use any pre- or post-procedure medication to mitigate the pain caused by disbudding. The disbudding procedure was performed mainly by farm personnel (94.9\%), who were trained by a veterinarian or veterinary technician $(46.9 \%)$ or by other farm personnel $(37.8 \%)$ or were not trained (15.3\%). Two-thirds of farmers observed behavioral changes in calves after disbudding. Most farmers estimated the pain caused by disbudding to be mild
\end{abstract}

Received May 11, 2017.

Accepted September 2, 2017.

${ }^{1}$ Corresponding author: stanek.stanislav@vuzv.cz or moderate (20.4 or $45.9 \%$, respectively) and $15.3 \%$ of farmers estimated it to be severe. Almost a quarter of interviewed farmers were unable to assess the duration of pain, $39.8 \%$ farmers estimated that the pain lasts only several minutes, and $20.4 \%$ estimated that the pain lasts up to $6 \mathrm{~h}$. We detected a tendency that farmers of larger herds estimated pain duration to be shorter (odds ratio $=1.2$ ). To improve calves' welfare, training is needed in disbudding practice, focusing on the advantage of pain mitigation.

Key words: calf, disbudding, farm management, welfare

\section{INTRODUCTION}

Disbudding involves the destruction of the cells of the horn bud (AVMA, 2014) and is defined as the removal of horns in calves up to 2 mo of age (Cozzi et al., 2015). Although it is not compulsory, it is routine practice in dairy cattle ( $81 \%$ of farms in the European Union; Cozzi et al., 2015) for several reasons: it decreases the risk of injury to humans during manipulation, it minimizes the risk of animals hurting each other (Gottardo et al., 2011; Cozzi et al., 2015), and it helps cattle adapt to contemporary housing facilities (ALCASDE, 2009; Stock et al., 2013).

The disbudding procedure is regulated by European Council Directive 98/58/EC (European Union, 1998) based on the Recommendation Concerning Cattle (Council of Europe Standing Committee, 1988) and by recommended guidelines in English-speaking countries; for example, The Code of Practice in Canada (Agriculture Canada, 1998) and guidelines from AVMA (2014) and AVA (2016). The practice, however, varies among countries (Misch et al., 2007; ALCASDE, 2009).

The most used method of disbudding is the hot-iron method; more than two-thirds of all calves in the European Union (EU; Cozzi et al., 2015), Canada (Vasseur et al., 2010), and the United States (USDA, 2008) are disbudded using this method. Use of caustic paste and mechanical methods of disbudding (scoop/tube) are 
less common, at 16.0 and $3.5 \%$, respectively, in the EU (Cozzi et al., 2015). Disbudding is frequently performed by farm personnel (Gottardo et al., 2011; Cozzi et al., 2015) but, despite the fact that disbudding is a serious procedure, a low level of professional training on correct disbudding technique among farmers has been reported (26.8\%; Gottardo et al., 2011).

Regardless of the method, disbudding is a painful and stressful procedure (Petrie et al., 1996; Hudson et al., 2008; Stafford and Mellor, 2011). Cautery disbudding may cause up to third-degree burns (Taschke and Folsch, 1997), caustic paste causes painful alkali burns, and mechanical dehorning is associated with large, bleeding head wounds. Disbudding is also accompanied by physiological stress responses; for example, cortisol release into the blood (Graf and Senn, 1999; Stafford and Mellor, 2005) and increased heart and respiratory rates (Grøndahl-Nielsen et al., 1999; Stewart et al., 2008) and can negatively affect growth (Bates et al., 2015). Behavioral responses, such as flicking, headjerks, rubbing, changing posture, and decrease in play behavior, can be observed after disbudding, all of which indicate impaired welfare of the calves (Stafford and Mellor, 2005; Vickers et al., 2005). Moreover, after disbudding, the calves show a negative judgement bias (Neave et al., 2013).

Therefore, strategies have been developed to mitigate the negative effects of disbudding. Most of the negative behavioral and physiological responses are reduced when local anesthetics or analgesics are administered (Stafford and Mellor, 2005). Use of this recommended medication, however, is very low: 20\% of European farms use some kind of anaesthetic or analgesic (ALCASDE, 2009); in the United States, $12.4 \%$ use anesthesia and $1.8 \%$ analgesics (Fulwider et al., 2008); and in Canada, 44.7\% use anesthesia and no analgesics (Vasseur et al., 2010). Despite scientific evidence, more than $40 \%$ of farmers consider the pain that accompanies disbudding to be moderate and last only few minutes (Hoe and Ruegg, 2006; Gottardo et al., 2011).

Previous research on farms (mean herd size $<100$ animals) showed that disbudding practices can be influenced by herd size and breed; however, the results are not consistent (Gottardo et al., 2011; Hokkanen et al., 2015). Another variable might be whether the farmer disbuds only heifers or both heifers and bulls, which has not been tested in previous studies. It is obvious that to increase calves' welfare, it is necessary to investigate different disbudding practices and potential for improvement. Therefore, the aim of this study was to evaluate disbudding practices on dairy farms in the Czech Republic and to assess these practices, including the use of pain alleviation medication by breed, herd size, and sex of the disbudded calves.

\section{MATERIALS AND METHODS}

\section{Characteristics of Herds and Design of the Study and Questionnaire}

Basic characteristics of dairy herds involved in the milk recording system in the Czech Republic are presented in Table 1. Representatives of 117 Czech dairy farms, representing $10.2 \%$ of all dairy farms in the Czech Republic were interviewed by a trained interviewer at dairy meetings in 2014 and 2015. We chose interviewing as a feasible alternative to a mailed questionnaire because the response rate is usually low for questionnaires; for example, 45\% in Finland (Hokkanen et al., 2015), $67.3 \%$ in the United States (Caraviello et al., 2006), and $42.6 \%$ in Italy (Gottardo et al., 2011). All evaluated farms were enrolled in the milk recording system. The design of the questionnaire is presented in Table 2.

As some farmers may not want to admit mistakes or problems on their farms, some of the results reported

Table 1. Comparison of numerical characteristics of national farms, studied dairy farms, and studied farms by breed

\begin{tabular}{|c|c|c|c|c|}
\hline \multirow[b]{2}{*}{ Item } & \multirow[b]{2}{*}{ National $^{1}$} & \multicolumn{3}{|c|}{ Study farms } \\
\hline & & All farms & Czech Fleckvieh & Holstein \\
\hline Cows, no. & 356,594 & 43,187 & 20,071 & 23,116 \\
\hline Herd size, ${ }^{2}$ no. of cows & 311 & $407.4 \pm 232.7$ & $352.1 \pm 183.6$ & $471.8 \pm 266.9$ \\
\hline Milk production, ${ }^{2} \mathrm{~kg} /$ cow per year & 8,001 & $8,171.8 \pm 1,527.3$ & $6,992.1 \pm 659.6$ & $9,544.1 \pm 1,010.0$ \\
\hline Age at weaning of calves, ${ }^{2} \mathrm{~d}$ & $\mathrm{NA}^{3}$ & $70.0 \pm 16.4$ & $71.4 \pm 18.4$ & $68.3 \pm 13.8$ \\
\hline
\end{tabular}

\footnotetext{
${ }^{1}$ Animals included in Czech milk recording system; data from the Czech-Moravian Breeders' Corporation (Kvapilík et al., 2016).

${ }^{2}$ Mean values $\pm \mathrm{SD}$.

${ }^{3}$ Not available.
} 
herein, which are based on farmers' answers, may be subject to a farmer's bias and thus may not completely reflect reality on farms.

In total, 106 questionnaires, which represent $9.2 \%$ of all farms in the Czech Republic, were used for further analysis (11 farms were excluded from the study because 10 farms kept mixed herds of Holstein and Czech Fleckvieh in varying proportions and 1 farm disbudded only bulls). In total, 43,187 cows were considered, $53.5 \%$ were Holstein and $46.5 \%$ were Czech Fleckvieh (Table 1). The average herd size of studied farms was 407 cows, which is greater than the mean value for the Czech Republic (Table 1). All farms included in this survey used loose housing of calves and no organic farms were included.

\section{Statistical Analysis}

One hundred six farms were included in the analysis and were handled anonymously. We calculated the descriptive statistics as mean \pm standard deviations for numerical variables and frequency and percentage for categorical variables (Table 3). To test the influence of breed (Czech Fleckvieh vs. Holstein), herd size, and the sex of disbudded calves (heifers and bulls vs. only heifers) on different variables, logistic regression models were used (procedure GENMOD in SAS; version 9.3, SAS Institute Inc., Cary, NC). Binary logistic regression models were used for testing the age of disbudding (up to 4 wk or after 4 wk), methods of disbudding (hot iron/caustic paste), and observed behavioral changes in calves after disbudding [yes (head waggling + head rubbing against the wall + drooping ears + aversion of milk + other behavioral changes)/no (cannot assess + do not observe any changes)]. Multinomial logistic regression models were used to test the painfulness of disbudding [not painful + mild pain; moderate pain; severe pain and the duration of pain (minutes, up to $6 \mathrm{~h}$, up to $12 \mathrm{~h}+$ more than $12 \mathrm{~h}$ )]; the categories "cannot assess" for severity and duration were not evaluated. Some variables were combined due to the small number of observations in each category, and some variables could not be tested because of the small number of observations; for example, performance of disbudding on the farm, use of anesthetics pre-disbudding, use of analgesics pre-disbudding, use of analgesics postdisbudding, use of antibiotics post-disbudding, who disbudded the calves, and how the farm personnel were trained. Odds ratios were calculated only for significant results or results that showed a tendency. For numerical variables, the odds ratio was calculated for herd size when increased by 100 cows. All statistics were calculated using SAS software (SAS Institute Inc.).

\section{RESULTS AND DISCUSSION}

\section{Prevalence of Disbudding}

According to our survey, disbudding was performed on $92.5 \%$ of the surveyed farms, which corresponds with ALCASDE (2009), which reported 93\% of farms with dehorned cattle in the Czech Republic. Our results are similar to findings in Italy $(95.5 \%$; Gottardo et al., 2011), France (96\%; Le Cozler et al., 2012), United States (94\%; USDA, 2008), and southern Brazil (98\%; Hötzel et al., 2014) but slightly higher than average for EU member states (88.8\%; Cozzi et al., 2015) or Finland (72\%; Hokkanen et al., 2015). This may be influenced by the housing of cows; all our surveyed farms used loose housing systems, which, according to previous studies, have a higher prevalence of dehorning/disbudding than tie-stall farms (Gottardo et al., 2011; Cozzi et al., 2015; Hokkanen et al., 2015). Previous research also showed a positive effect of herd size on prevalence of disbudding, but for a much lower mean herd size than in our sample (407 cows/farm).

Table 2. Design of the questionnaire about farm practice in calf disbudding

\begin{tabular}{|c|c|}
\hline Area of management & Criterion (variable) \\
\hline Dairy farm basic characteristics & Herd size, breed, milk performance, age at weaning, age at disbudding \\
\hline Disbudding practice on dairy farms & $\begin{array}{l}\text { Disbudded before or after d } 28 \text {, housing of disbudded calves, sex, method of dehorning or } \\
\text { disbudding, who is disbudding the calves, how was this person trained, use of anesthetics } \\
\text { before disbudding, use of analgesics before or after disbudding, use of disinfection or } \\
\text { antibiotics after disbudding }\end{array}$ \\
\hline \multicolumn{2}{|r|}{ 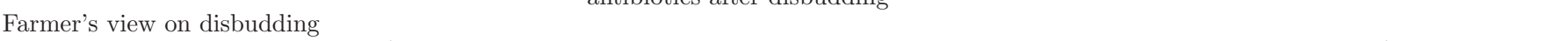 } \\
\hline What can be observed in calves after disbudding & $\begin{array}{l}\text { Head waggling, head rubbing against the wall, drooping ears, aversion of milk, other } \\
\text { behavioral changes, cannot assess, don't observe any changes }\end{array}$ \\
\hline Whether the disbudding is painful & Not painful, mild pain, moderate pain, severe pain, cannot assess \\
\hline How long the pain lasts & Minutes, up to $6 \mathrm{~h}$, up to $12 \mathrm{~h}$, more than $12 \mathrm{~h}$, cannot assess \\
\hline
\end{tabular}


Table 3. Categorical characteristics of studied dairy farms with disbudding practice

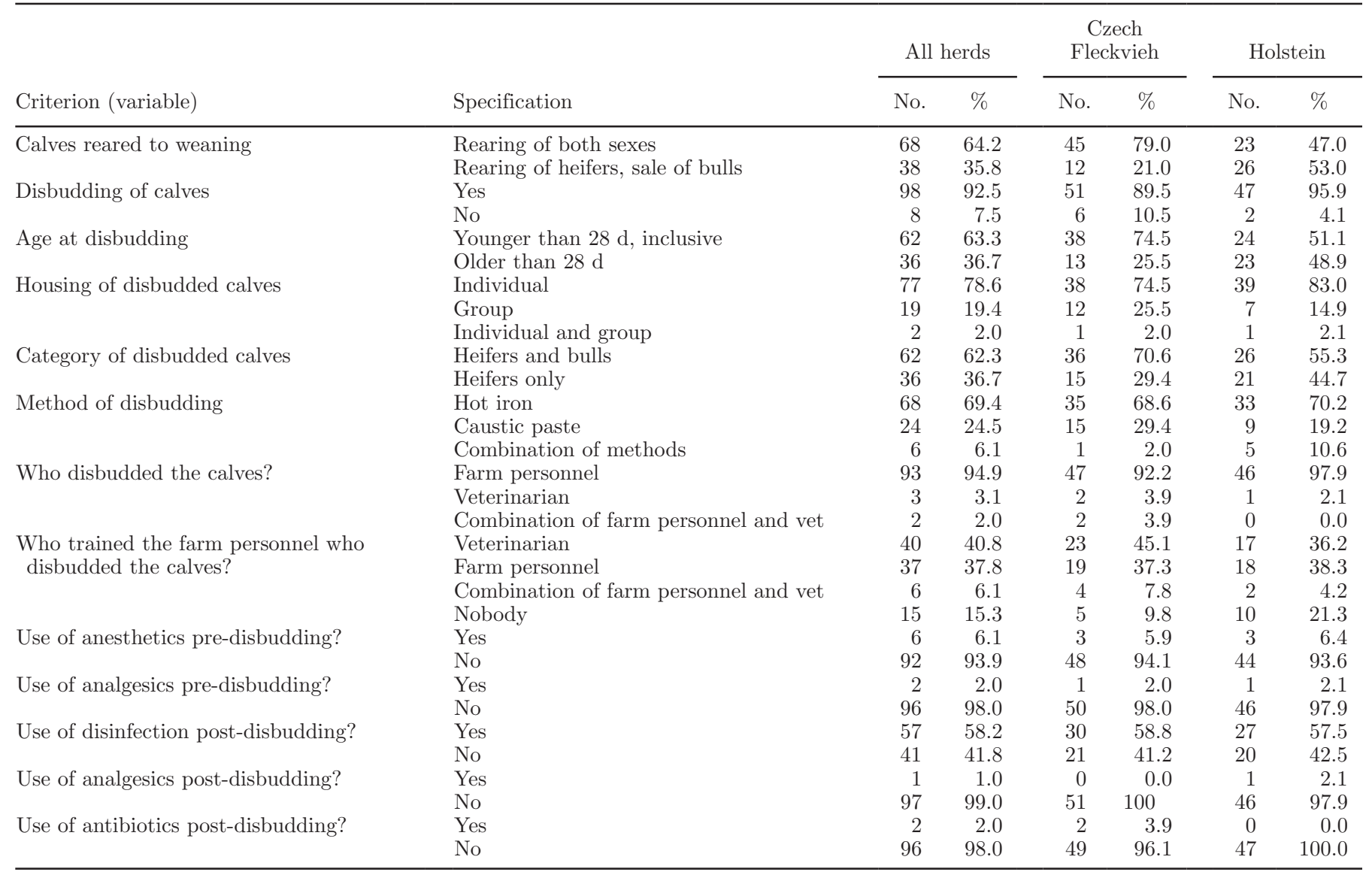

Gottardo et al. (2011) showed the odds ratio to be 7.3 times greater for calves to be dehorned in herds with $>60$ cows compared with those in smaller herds. Hokkanen et al. (2015) reported $100 \%$ probability of calves on farms with $>60$ cows being dehorned. Gottardo et al. (2011) showed that the likelihood of being dehorned is lower on farms rearing dual-purpose breeds than in those with pure milk breeds $(65.1 \%$ vs. $88.4 \%$, respectively). However, we could not test these variables because the data set of our surveyed farms was noticeably unbalanced (98 farms performed disbudding and 8 farms did not).

\section{Age at Disbudding}

The mean age at disbudding was 3.6 wk (median $20 \mathrm{~d} ; 2.9$ wk; Table 1), which is lower than $6.4 \mathrm{wk}$ (median) in Canada (Vasseur et al., 2010) and $4.6 \mathrm{wk}$ (mean) in Italy (Gottardo et al., 2011). The age range when calves were disbudded on surveyed Czech farms, however, was very wide, from 3 to $68 \mathrm{~d}$ of age. In our study, $63.3 \%$ of calves were disbudded before 4 wk of age, which is higher than some previous reports: $21 \%$ in Canada (Misch et al., 2007) and 17\% in southern Brazil (Hötzel et al., 2014), but lower than in Finland, where Hokkanen et al. (2015) reported that $95 \%$ of respondents disbudded calves before the age of 4 wk. The main reason that most calves were disbudded before 4 wk of age may be that EU and Czech legislation allows the disbudding of calves without the use of pain-mitigating medication until this age. We found that Czech Fleckvieh calves were 2.8 times more likely than Holstein calves to be disbudded before 4 wk of age $(P=0.02$; Table 4$)$. This result does not correspond with the findings of a study in Italy, where breed did not affect the age of calves at disbudding (Gottardo et al., 2011). However, our result may be caused by some differences in approach and attitude of calf management between farmers who keep dairy breeds (Holstein) and those who keep dual-purpose breeds (Czech Fleckvieh), as has been shown in a previous study (Staněk et al., 2014). Herd size and sex of disbudded calves did not significantly influence age at disbudding $(P>0.1$; Table 4$)$. 


\section{Method of Disbudding}

Of the surveyed farms in the Czech Republic, $69.4 \%$ used the hot-iron method for disbudding, which corresponds with $69.1 \%$ reported in the United States (USDA, 2008) but is lower than that reported in Canada (88.7\%; Vasseur et al., 2010), southern Brazil (95\%; Hötzel et al., 2014), Italy (90.6\%; Gottardo et al., 2011), France (87\%, Le Cozler et al., 2012; 87.6\%, de Boyer des Roches et al., 2014), and EU member states (80.4\%; Cozzi et al., 2015). The chemical method (caustic paste) was used on $24.5 \%$ farms, which is significantly higher than reported in other studies: 16\% (Cozzi et al., 2015), 12.2\% (USDA, 2008), 11\% (Le Cozler et al., 2012), 11.6\% de Boyer des Roches et al., 2014), 9\% (Misch et al., 2007; Gottardo et al., 2011), and 6.1\% (Vasseur et al., 2010). The use of the chemical method is influenced by specific legislation in several European countries (e.g., Germany, Austria, the United Kingdom) that restricts the use of caustic paste (ALCASDE, 2009). Some countries, such as Italy (ALCASDE, 2009) and Canada (NFACC, 2009), do not restrict the use of caustic paste. The application of caustic paste is associated with the need for individual housing of treated calves in the hours following the procedure to prevent accidental caustic burns to other animals (NFACC, 2009). According to our survey, $91.7 \%$ of herds disbudded only by the chemical method (caustic paste) housed their calves individually.

We found that the sex of disbudded calf influenced the method of disbudding. Calves were 4.5 times more likely to be disbudded by hot iron in herds where both heifers and bulls were disbudded than in herds where only heifers were disbudded $(P=0.003$; Table 4$)$. This result may be influenced by the duration of the procedure; the hot-iron method is less time consuming than, for example, chemical methods. Breed and herd size did not have a significant effect on the disbudding method used $(P>0.1$; Table 4$)$.

Additionally, hot-iron cauterization is associated with the need for disinfection of surgical wounds to prevent inflammation and blow fly myiasis. We found that $70.6 \%$ farms that dehorned calves by hot iron used disinfection after the intervention. Regardless of the method used, the prevalence of using postoperative local disinfection is $70 \%$ in EU Member states (Cozzi et al., 2015).

\section{Use of Medication}

The majority (>90\%) of surveyed farms did not use any pre- or post-procedure medication to mitigate pain (Table 3), a level even lower than the findings of Gottardo et al. (2011) in Italy, which reported the use of anesthetics in $10.4 \%$ of surveyed farms and predisbudding analgesics in 5\%; in most cases, no postoperative medication was administered. Compared with these findings, the use of medication was slightly higher in the United States: Hoe and Ruegg (2006) reported the use of anesthetics on $17.9 \%$ of surveyed farms in Wisconsin and, according to USDA (2008), $17.7 \%$ of all farms in United States use analgesics or anesthetics during disbudding. In Canada, Misch et al. (2007) reported that $22 \%$ of dairy producers used local anesthetics; in France, $24 \%$ of farmers used anesthetics or analgesics (de Boyer des Roches et al., 2014); and in a Canadian survey by Vasseur et al. (2010), 44.7\% of re-

Table 4. Disbudding practice according to breed, herd size, and category of disbudded calves

\begin{tabular}{|c|c|c|c|c|c|}
\hline Variable & No. of farms & Statistics & Breed $^{1}$ & Herd size & Sex of disbudded calves \\
\hline $\begin{array}{l}\text { Age at disbudding: } \\
\text { Modeling the probability to } 28 \mathrm{~d}\end{array}$ & 98 & $\begin{array}{l}\text { Results } \\
\text { df } \\
\chi^{2} \\
P \text {-value } \\
\text { Odds ratio }^{2}\end{array}$ & $\begin{array}{l}\quad \mathrm{C}>\mathrm{H} \\
1 \\
5.28 \\
0.023^{*} \\
2.800 \\
(1.146 ; 6.843)\end{array}$ & $\begin{array}{l}\text { NS } \\
1 \\
0.62 \\
0.433 \\
\mathrm{NR}^{3}\end{array}$ & $\begin{array}{l}\quad \text { NS } \\
1 \\
1.07 \\
0.301 \\
\quad \text { NR }\end{array}$ \\
\hline $\begin{array}{l}\text { Methods: Modeling the } \\
\text { probability of hot-iron }\end{array}$ & 92 & $\begin{array}{l}\text { Results } \\
\text { df } \\
\chi^{2} \\
P \text {-value } \\
\text { Odds ratio }\end{array}$ & $\begin{array}{l}1 \quad \mathrm{NS} \\
1 \\
0.96 \\
0.327 \\
\quad \mathrm{NR}\end{array}$ & $\begin{array}{l}\text { NS } \\
1 \\
1.68 \\
0.195 \\
\text { NR }\end{array}$ & $\begin{array}{l}\text { Heifers and bulls }>\text { heifers } \\
\qquad \begin{array}{l}1 \\
8.59 \\
0.003^{* *} \\
4.450 \\
(1.594 ; 12.422)\end{array}\end{array}$ \\
\hline
\end{tabular}

${ }^{1} \mathrm{C}=$ Czech Fleckvieh; $\mathrm{H}=$ Holstein.

${ }^{2}$ Numbers in parentheses are confidence limits for odds ratio.

${ }^{3} \mathrm{NR}=$ not relevant.

${ }^{*} P<0.05,{ }^{*} P<0.01$. 
spondents reported the use of pre-dehorning anesthetics but no analgesics. Overall, ALCASDE (2009) reported that $20 \%$ of European dairy farms used pain-mitigating drugs during the disbudding procedure. Higher prevalence $(33 \%)$ of pain medication usage was reported in northern countries (e.g., Denmark, Estonia, Finland, Ireland, Sweden, and the UK) and the lowest (13\%) prevalence was reported in southern countries (e.g., Cyprus, Greece, Italy, Portugal, and Spain; ALCASDE, 2009). According to the research in in Brazil, no pain control was used for disbudding calves by smallholder/ family farmers (Hötzel et al., 2014).

Despite previous research suggesting that calves should be considered in exactly the same manner as adult cattle (Graf and Senn, 1999; Hudson et al., 2008) and showing that pain may be even greater in neonatal animals (Murray and Leslie, 2013), European Council Directive 98/58/EC (European Union, 1998) allows the destruction or removal of the horn-producing area of animals younger than $4 \mathrm{wk}$ of age without using any anesthesia. This may be one of the reasons for the limited usage of pain-relieving medication, despite the analgesia not only reducing the pain, but also attenuating suppressed leukocyte function during the procedure (Hulbert and Moisá, 2015).

The extra cost and the reluctance of veterinarians to perform disbudding could be another reason for the infrequent usage of analgesic and anesthetics drugs. In the Czech Republic, the average cost for the disbudding procedure, including the cost of medication (xylazine, procaine/lidocaine) and application of medication by a veterinarian is US $\$ 3.95$ to $\$ 4.35$ (US $\$ 1=25.30 \mathrm{CZK}$ ), where the cost of medication accounts for 20 to $25 \%$ of the total cost, application 30 to $35 \%$, and cautery and disinfection 40 to $50 \%$. This cost is probably perceived by farmers as relatively high. This corresponds with previous results from Misch et al. (2007), who showed the cost of medication to be the most common reason for lack of use among producers in Ontario, Canada. However, another Canadian study confirmed this result only partly, because only $41 \%$ of veterinarians who do not use analgesic before disbudding agree (35.6\% disagree), whereas only $23.9 \%$ of those who use analgesics definitely agree (53.9\% disagree) with the proposition that farmers are unwilling to pay for analgesia (Hewson et al., 2007). Gottardo et al. (2011) showed that farmers were willing to pay less than half the true cost of treatment ( $\$ 0.35$ to $\$ 1.40$ vs. the standard cost of medications of $\$ 2.90$ per calf). Another problem is that in some countries (including the Czech Republic), the farmers are not allowed to give the medication to the calves themselves - only a veterinarian can administer the drugs legally (e.g., in Finland; Seppä-Lassila et al., 2016) and it is perceived by farmers as too expensive to have a veterinarian medicate calves before disbudding (Wikman et al., 2013; Hokkanen et al., 2015). A solution for this problem was suggested in Switzerland where the "anesthesia delegation model" (ADM) was introduced, where anesthesia may be administered by certified farmers. Alsaaod et al. (2014) concluded that this is a promising model for increasing the usage of anesthesia during disbudding of calves. Currently, the topic is very important-in a North American survey, the majority (90\%) of responders, which included both industry and non-industry stakeholders, thought that pain relief should be provided when disbudding and dehorning dairy calves (Robbins et al., 2015).

Previous research indicated a negative influence of herd size on the usage of local anesthetic (Gottardo et al., 2011), but Hoe and Ruegg (2006) did not find any statistical difference in the use of local anesthetics or tranquilizers between small and large herds. Because of the extremely limited usage of medication in our data set, we were not able to test this prediction.

\section{Who Disbudded the Calves and How Were They Trained?}

In the Czech Republic, the disbudding procedure was performed mainly by farm personnel (94.9\%), which is comparable to other studies (Gottardo et al., 2011; Cozzi et al., 2015; Winder et al., 2016). The participation of a veterinarian or veterinary technician (graduate from secondary veterinary school) in the disbudding procedure was of minor importance (3.1\%), even though recent research showed a positive influence on disbudding performed by veterinarian compared with farm personnel; for example, greater milk consumption and faster growth (Bates et al., 2015) or lower mortality risk (Seppä-Lassila et al., 2016). A low percentage of participation by veterinarians $(1.4 \%)$ was reported in the largest herds in the United States (>500 cows; USDA, 2008), which corresponds with our result (our surveyed herds averaged 407 cows per farm).

The farm personnel who disbudded the calves were, in $46.9 \%$ of cases, trained by professional staff (veterinarian or veterinary technician), $37.8 \%$ were trained by other farm personnel, and $15.3 \%$ did not receive training. Previous research from Italy showed that $30.2 \%$ of farmers were trained by professional staff (veterinarian or milk quality inspector), $43 \%$ of respondents received training from another farmer, and $26.8 \%$ received no training and learned the technique on their own (Gottardo et al., 2011). In contrast, when focusing just on 
Table 5. Farmers' opinions on behavioral responses and painfulness of disbudding procedure

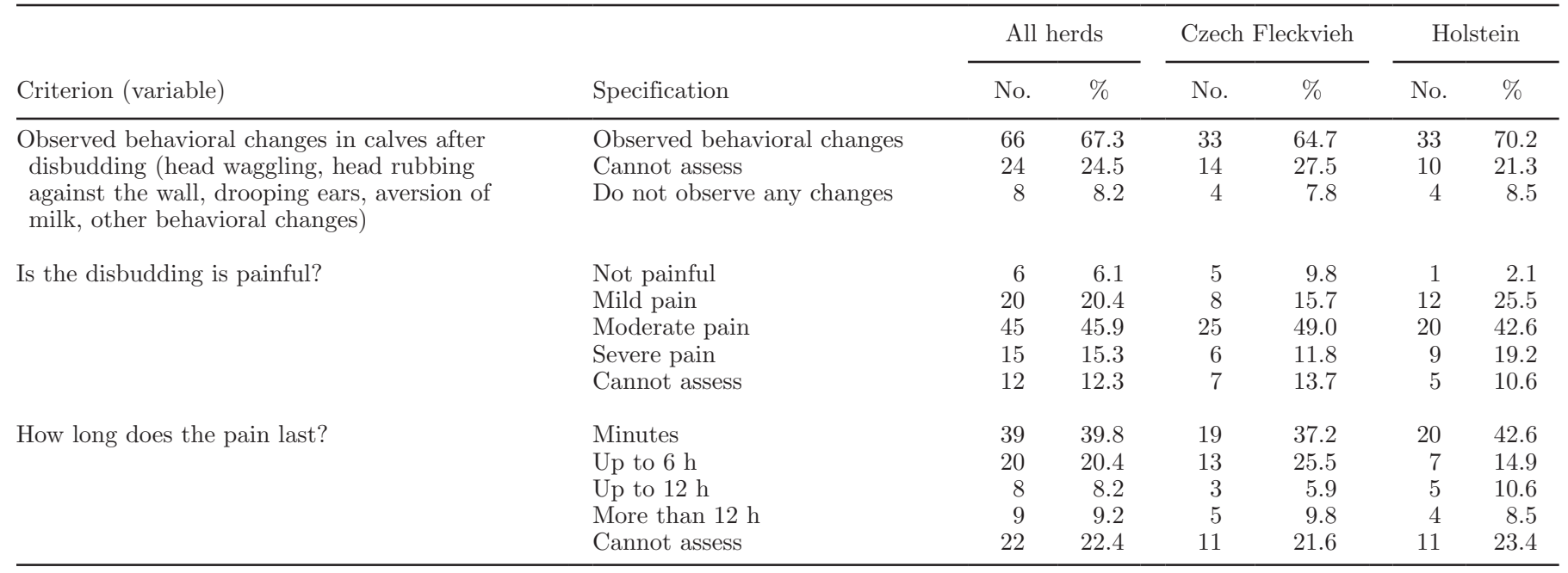

larger farms ( $>200$ cows), $40 \%$ of farmers were trained by veterinarians and $20 \%$ of farmers did not receive training (Gottardo et al., 2011), which corresponds with our results and our average herd size.

\section{Farmers' Opinions on Disbudding Procedure}

We also investigated farmers' perceptions of the pain associated with the disbudding procedure and what behavior they observed thereafter. The results are listed in Table 5. Previous research has shown that the pain accompanying disbudding causes several physiological and negative behavioral responses, regardless of the method used (e.g., Vickers et al., 2005; Stafford and Mellor, 2005, 2011; Heinrich et al., 2010; Mintline et al., 2013; Caray et al., 2015). In line with this, two-thirds of surveyed farmers were able to observe the calves' behavioral responses such as head shaking or rubbing against a wall, loss of appetite (aversion of milk), drooping ears, or other behavioral changes. In contrast, $24.5 \%$ were not able to assess and $8.2 \%$ did not observe any behavioral changes, a very low incidence

Table 6. Farmer's opinion according to breed, herd size, and category of disbudded calves

\begin{tabular}{|c|c|c|c|c|c|}
\hline Variable & No. of farms & Statistics & Breed & Herd size & Sex of disbudded calves \\
\hline $\begin{array}{l}\text { Painfulness of disbudding: } \\
\text { Modeling the probability } \\
\text { of higher value-greater pain }\end{array}$ & 86 & $\begin{array}{l}\text { Results } \\
\text { df } \\
\chi^{2} \\
P \text {-value } \\
\text { Odds ratio }^{2}\end{array}$ & $\begin{array}{l}\text { NS } \\
1 \\
0.28 \\
0.598 \\
\text { NR }\end{array}$ & $\begin{array}{l}1 \quad \text { NS } \\
0.11 \\
0.738 \\
\quad \text { NR }\end{array}$ & $\begin{array}{l}\text { Heifers and bulls }>\text { heifers } \\
1 \\
3.05 \\
0.081 \dagger \\
2.158 \\
(0.903 ; 5.154)\end{array}$ \\
\hline $\begin{array}{l}\text { How long does the pain last? } \\
\text { Modeling the probability of } \\
\text { lower value-shorter period }\end{array}$ & 76 & $\begin{array}{l}\text { Results } \\
\mathrm{df} \\
\chi^{2} \\
P \text {-value } \\
\text { Odds ratio }\end{array}$ & $\begin{array}{l}\text { NS } \\
1 \\
0.04 \\
0.847 \\
\text { NR }\end{array}$ & $\begin{array}{l}\text { Larger }>\text { smaller } \\
\quad 1 \\
3.59 \\
0.058 \dagger \\
1.229 \\
(0.982 ; 1.539)\end{array}$ & $\begin{array}{l}1 \\
1.26 \\
0.262 \\
\quad \mathrm{NR}\end{array}$ \\
\hline
\end{tabular}

${ }^{1} \mathrm{NR}=$ not relevant.

${ }^{2}$ Numbers in parentheses are confidence limits for odds ratio.

$\dagger P<0.10$. 
compared with a previous study where $26.3 \%$ of Italian farmers with herd size $>200$ cows never observed any behavioral changes (Gottardo et al., 2011). We did not find a significant influence of breed, herd size, or sex of disbudded calves on the farmer's ability to observe any behavioral changes after disbudding $(P>0.1$; Table $6)$, which is in agreement with a previous study where breed and herd size did not have a significant influence on behavior observed after disbudding (Gottardo et al., 2011).

Most surveyed farmers estimated the accompanying pain to be mild or moderate (20.4 and $45.9 \%$ of respondents, respectively). These results are in accordance with other previous studies; for example, in the United States, $42 \%$ of respondents estimated that disbudding causes little or no pain and $40 \%$ considered it to involve moderate pain (Hoe and Ruegg, 2006), or in Italy, where more than $40 \%$ of farmers perceived postoperative pain to be moderate (Gottardo et al., 2011). In contrast, a study from Finland showed a better understanding of the pain involved in disbudding procedures: $69 \%$ of respondents estimated disbudding-related pain to be severe, and $63 \%$ agreed with the statement "The calf requires pain medication for disbudding" (Hokkanen et al., 2015). Similar results were found in another Finnish study by Wikman et al. (2013). When Canadian veterinarians were asked, $58 \%$ of respondents estimated the disbudding procedure to be "very painful" (Hewson et al., 2007). We found a tendency for the sex of the disbudded calves to influence farmers' opinion of how painful disbudding is for calves; on farms where both sexes were disbudded, the odds ratio for farmers to consider a higher level of pain intensity was 2.16 times higher than on farms where only heifers were disbudded $(P=0.08$; Table 6$)$. Breed and herd size did not influence the farmers' opinion on how painful disbudding is for calves $(P>0.1$; Table 6$)$.

In previous research, the maximum pain response was observed within the first $30 \mathrm{~min}$ after disbudding (Stafford and Mellor, 2011; Stock et al., 2013), followed by plateau level of pain for at least $3 \mathrm{~h}$ (Stilwell et al., 2009) or up to $8 \mathrm{~h}$ (Stock et al., 2013). Furthermore, differences in behavior, which may indicate pain in calves after disbudding, were detected $24 \mathrm{~h}$ after the procedure (Faulkner and Weary, 2000). However, little is known about chronic pain in the days following disbudding (Stafford and Mellor, 2011). The latest research shows that wounds after hot-iron disbudding remain painful for at least $3 \mathrm{wk}$ (S. J. J. Adcock and C. B. Tucker, both from Center for Animal Welfare, Animal Science, University of California, Davis, 2017, personal communication) and wounds after hot-iron branding are sensitive at least 8 wk (Tucker et al.,
2014). In our survey, $39.8 \%$ of farmers estimated that the pain lasts just minutes or up to $6 \mathrm{~h}(20.4 \%)$, which is slightly lower than in a previous study by Gottardo et al. (2011), where $48 \%$ estimated that the pain lasts only a few minutes or less than $6 \mathrm{~h}(43 \%)$. We found a tendency for the effect of herd size on farmers' opinion on how long the pain lasts $(P=0.058$; Table 6$)$ : the larger the herd size, the more likely was the farmer to estimate a shorter duration of pain. On the other hand Gottardo et al. (2011) and Hoe and Ruegg (2006) did not show an effect of herd size on farmers' opinion of postoperative pain duration. The breed and sex of the disbudded calves did not affect farmers' opinion on how long the pain lasts $(P>0.1$, Table 6$)$, which is in accordance with findings of Gottardo et al. (2011).

\section{CONCLUSIONS}

Our study was based on a sample of farms with larger herd sizes than previous studies. On dairy farms with hundreds of cows, actual herd size has little influence on disbudding practice and attitudes. Furthermore, the type of breed kept on a farm might influence disbudding practices, even though farmers' opinions about pain associated with disbudding did not differ by breed. Based on the low usage of painkilling drugs and farmers' attitudes to pain intensity and duration caused by disbudding, professional training in disbudding practice is needed for farm personnel, especially to show the advantages of using pre- and post-procedure pain-mitigating medication to decrease behavioral reactions and to improve calves' welfare and production characteristics. For further improvement of welfare in the period around disbudding, it is important for veterinarians to cooperate with farmers to highlight the importance of this topic and to open the discussion on using medications. The Swiss "anesthesia delegation model" can be seen as a positive example of progress.

\section{ACKNOWLEDGMENTS}

This study was supported by a research plan of the Ministry of Agriculture of the Czech Republic (Prague, Czech Republic; MZERO0717) and a research grant from the National Agency for Agricultural Research (Prague, Czech Republic; NAZV QJ1510219). We thank the dairy farmers for their participation in the survey. We also thank Marie Šimečková (Institute of Animal Science, Czech Republic), Cassandra B. Tucker (University of California), and Marek Špinka (Institute of Animal Science, Czech Republic) for their valuable comments. 


\section{REFERENCES}

Agriculture Canada. 1998. Recommended code of practice for the care and handling of dairy cattle, Publication 1853/E. Ottawa. Agriculture Canada 1998:17.

ALCASDE (Alternatives to Castration and Dehorning). 2009. D.2.1.1. Report on dehorning practices across EU member states. Appendix 20. Accessed Feb. 17, 2017. http://www.vuzv.sk/DB-Welfare/ telata/calves_alcasde_D-2-1-1.pdf.

Alsaaod, M., M. G. Doherr, D. Greber, and A. Steiner. 2014. Experience with the delegation of anaesthesia for disbudding and castration to trained and certified livestock owners. BMC Vet. Res. 10:35.

AVA. 2016. Policy Compendium Australian Veterinary Association. Accessed Mar. 22, 2017. http://www.ava.com.au/sites/default/ files/private/Policy\%20Compendium\%20January\%202016.pdf.

AVMA. 2014. Literature review on the welfare implications of the dehorning and disbudding of cattle Am. Vet. Med. Assoc. Accessed Dec. 5, 2016. https://www.avma.org/KB/Resources/ LiteratureReviews/Pages/Welfare-Implications-of-Dehorning-and -Disbudding-Cattle.aspx.

Bates, A. J., P. Eder, and R. A. Laven. 2015. Effect of analgesia and anti-inflammatory treatment on weight gain and milk intake of dairy calves after disbudding. N. Z. Vet. J. 63:153-157.

Caraviello, D. Z., K. A. Weigel, P. M. Fricke, M. C. Wiltbank, M J. Florent, N. B. Cook, K. V. Nordlund, N. R. Zwald, and C. L. Rawson. 2006. Survey of management practices on reproductive performance of dairy cattle on large US commercial farms. J. Dairy Sci. 89:4723-4735.

Caray, D., A. de Boyer des Roches, S. Frouja, S. Andanson, and I. Veissier. 2015. Hot-iron disbudding: Stress responses and behavior of 1- and 4-week-old calves receiving anti-inflammatory analgesia without or with sedation using xylazine. Livest. Sci. 179:22-28.

Council of Europe Standing Committee. 1988. Recommendation Concerning Cattle Adopted by the Standing Committee on 21 October 1988. Accessed Jan. 6, 2017. http://www.coe.int/t/e/ legal_affairs/legal_co-operation/biological_safety_and_use_of _animals/farming/Rec\%20cattle\%20E.asp.

Cozzi, G., F. Gottardo, M. Brscic, B. Contiero, F. Irrgang, U. Knierim, O. Pentelescu, J. J. Windig, L. Mirabito, F. Kling Eveillard, A. A. Dockes, I. Veissier, A. Velarde, C. Fuentes, A. Dalmau, and C. Winckler. 2015. Dehorning of cattle in the EU Member States: A quantitative survey of the current practices. Livest. Sci. 179:4-11.

de Boyer des Roches, A., I. Veissier, M. Coignard, N. Bareille, R Guatteo, J. Capdeville, E. Gilot-Fromont, and L. Mounier. 2014. The major welfare problems of dairy cows in French commercial farms: an epidemiological approach. Anim. Welf. 23:467-478.

European Union. 1998. Directive 98/58/EC, 1998. Council Directive 98/58/EC of 20 July 1998 concerning the protection of animals kept for farming purposes. Off. JL 221: 8.8.1998 (Article 3; Annex I $\left.\mathrm{N}^{\circ} 19\right)$.

Faulkner, P. M., and D. M. Weary. 2000. Reducing pain after dehorning in dairy calves. J. Dairy Sci. 83:2037-2041.

Fulwider, W. K., T. Grandin, B. E. Rollin, T. E. Engle, N. L. Dalsted, and W. D. Lamm. 2008. Survey of dairy management practices on one hundred thirteen north central and northeastern United States dairies. J. Dairy Sci. 91:1686-1692.

Gottardo, F., E. Nalon, B. Contiero, S. Normando, P. Dalvit, and G. Cozzi. 2011. The dehorning of dairy calves: Practices and opinions of 639 farmers. J. Dairy Sci. 94:5724-5734.

Graf, B., and M. Senn. 1999. Behavioural and physiological responses of calves to dehorning by heat cauterization with or without local anaesthesia. Appl. Anim. Behav. Sci. 62:153-171.

Grøndahl-Nielsen, C., H. B. Simonsen, J. Damkjer Lund, and H. Hesselholt. 1999. Behavioural, endocrine and cardiac responses in young calves undergoing dehorning without and with the use of sedation and analgesia. Vet. J. 158:14-20.

Heinrich, A., T. F. Duffield, K. D. Lissemore, and S. T. Millman. 2010. The effect of meloxicam on behavior and pain sensitivity of dairy calves following cautery dehorning with a local anesthetic. J. Dairy Sci. 93:2450-2457.

Hewson, C. J., I. R. Dohoo, K. A. Lemke, and H. W. Barkema. 2007. Factors affecting Canadian veterinarians' use of analgesics when dehorning beef and dairy calves. Can. Vet. J. 48:1129-1136.

Hoe, F. G. H., and P. L. Ruegg. 2006. Opinions and practices of Wisconsin dairy producers about biosecurity and animal well-being. J. Dairy Sci. 89:2297-2308.

Hokkanen, A. H., I. Wikman, T. Korhonen, M. Pastell, A. Valros, O. Vainio, and L. Hänninen. 2015. Perceptions and practices of Finnish dairy producers on disbudding pain in calves. J. Dairy Sci. 98:823-831.

Hötzel, M. J., C. Longo, L. F. Balcão, C. S. Cardoso, and J. H. C Costa. 2014. A Survey of management practices that influence performance and welfare of dairy calves reared in Southern Brazil. PLoS One 9:e114995.

Hudson, C., H. Whay, and J. Huxley. 2008. Recognition and management of pain in cattle. In Pract. 30:126-134.

Hulbert, L. E., and S. J. Moisá. 2015. Stress, immunity, and the management of calves. J. Dairy Sci. 99:3199-3216.

Kvapilík, J., J. Kučera, P. Bucek, M. Abrahamová, V. Škaryd, Z. Veselá, L. Koudelová, L. Vondrášek, F. Hřeben, T. Kopec, and P. Král. 2016. Chov skotu v České republice - hlavní výsledky a ukazatele za rok 2015. Czech-Moravian Breeders Society, Institute of Animal Science, Prague-Uhř́něves, Breeders' Association of Czech Fleckvieh Cattle, Breeders' Association of Holstein Cattle in the Czech Republic, Czech Beef Breeders Association, Prague, Czech Republic.

Le Cozler, Y., O. Recoursé, E. Ganche, D. Giraud, J. Daniel, M. Bertin, and P. Brunschwig. 2012. A survey on dairy heifer farm management practices in a Western-European plainland, the French Pays de la Loire region. J. Agric. Sci. 150:518-533.

Mintline, E. M., M. Stewart, A. R. Rogers, N. R. Cox, G. A. Verkerk, J. M. Stookey, J. R. Webster, and C. B. Tucker. 2013. Play behavior as an indicator of animal welfare: Disbudding in dairy calves. Appl. Anim. Behav. Sci. 144:22-30.

Misch, L. J., T. F. Duffield, S. T. Millman, and K. D. Lissemore. 2007. An investigation into the practices of dairy producers and veterinarians in dehorning dairy calves in Ontario. Can. Vet. J. 48:1249-1254

Murray, C. F., and K. E. Leslie. 2013. Newborn calf vitality: Risk factors, characteristics, assessment, resulting outcomes and strategies for improvement. Vet. J. 198:322-328.

Neave, H. W., R. R. Daros, J. H. C. Costa, M. A. G. von Keyserlingk, and D. M. Weary. 2013. Pain and pessimism: Dairy calves exhibit negative judgement bias following hot-iron disbudding. PLoS One 8:e80556.

NFACC. 2009. Code of practice for the care and handling of dairy cattle. National Farm Animal Care Council. Accessed Mar. 3, 2017. http://www.nfacc.ca/pdfs/codes/dairy_code_of_practice.pdf.

Petrie, N. J., D. J. Mellor, K. J. Stafford, R. A. Bruce, and R. N. Ward. 1996. Cortisol responses of calves to two methods of disbudding used with or without local anaesthetic. N. Z. Vet. J. 44:9-14.

Robbins, J. A., D. M. Weary, C. A. Schuppli, and M. A. G. von Keyserlingk. 2015. Stakeholder views on treating pain due to dehorning dairy calves. Anim. Welf. 24:399-406.

Seppä-Lassila, L., K. Sarjokari, M. Hovinen, T. Soveri, and M. Norring. 2016. Management factors associated with mortality of dairy calves in Finland: A cross sectional study. Vet. J. 216:164-167.

Stafford, K. J., and D. J. Mellor. 2005. Dehorning and disbudding distress and its alleviation in calves. Vet. J. 169:337-349.

Stafford, K. J., and D. J. Mellor. 2011. Addressing the pain associated with disbudding and dehorning in cattle. Appl. Anim. Behav. Sci. 135:226-231.

Staněk, S., V. Zink, O. Doležal, and L. Štolc. 2014. Survey of preweaning dairy calf-rearing practices in Czech dairy herds. J. Dairy Sci. 97:3973-3981.

Stewart, M., K. J. Stafford, S. K. Dowling, A. L. Schaefer, and J. R. Webster. 2008. Eye temperature and heart rate variability of 
calves disbudded with or without local anaesthetic. Physiol. Behav. 93:789-797.

Stilwell, G., R. C. Carvalho, M. S. Lima, and D. M. Broom. 2009. Effect of caustic paste disbudding, using local anaesthesia with and without analgesia, on behaviour and cortisol of calves. Appl. Anim. Behav. Sci. 116:35-44.

Stock, M. L., S. L. Baldridge, D. Griffin, and J. F. Coetzee. 2013. Bovine dehorning assessing pain and providing analgesic management. Vet. Clin. North Am. Food Anim. Pract. 29:103-133.

Taschke, A. C., and D. W. Folsch. 1997. Ethological, physiological and histological aspects of pain and stress in cattle when being dehorned. Tierarztl. Prax. 25:19-27.

Tucker, C. B., E. M. Mintline, J. Banuelos, K. A. Walker, B. Hoar, A. Varga, D. Drake, and D. M. Weary. 2014. Pain sensitivity and healing of hot-iron cattle brands. J. Anim. Sci. 92:5674-5682.

USDA. 2008. Dairy 2007, Part IV: Reference of Dairy Cattle Health and Management Practices in the United States, 2007. Accessed
Aug. 31, 2016. https://www.aphis.usda.gov/animal_health/ nahms/dairy/downloads/dairy07/Dairy07_dr_PartIV.pdf.

Vasseur, E., F. Borderas, R. I. Cue, D. Lefebvre, D. Pellerin, J. Rushen, K. M. Wade, and A. M. de Passillé. 2010. A survey of dairy calf management practices in Canada that affect animal welfare. J. Dairy Sci. 93:1307-1316.

Vickers, K. J., L. Niel, L. M. Kiehlbauch, and D. M. Weary. 2005. Calf response to caustic paste and hot-iron dehorning using sedation with and without local anesthetic. J. Dairy Sci. 88:1454-1459.

Wikman, I., A. H. Hokkanen, M. Pastell, T. Kauppinen, A. Valros, and L. Hänniken. 2013. Dairy producer attitudes to pain in cattle in relation to disbudding calves. J. Dairy Sci. 96:6894-6903.

Winder, Ch. B., S. J. LeBlanc, D. B. Haley, K. D. Lissemore, M. A. Godkin, and T. F. Guffield. 2016. Practices for the disbudding and dehorning of dairy calves by veterinarians and dairy producers in Ontario, Canada. J. Dairy Sci. 99:10161-10173. 